\title{
Formation of a Comfortable Urban Environment for Persons with Disabilities in the Strategy of Socio- economic Development of Voronezh
}

\author{
Yuri I. Treshchevsky \\ Department of Economics and Organization Management \\ Voronezh State University \\ Voronezh, Russia \\ E-mail: utreshevski@yandex.ru
}

\author{
Anna Yu. Kosobutskaya \\ Department of Economics and Organization Management \\ Voronezh State University \\ Voronezh, Russia \\ E-mail: kosobutskaya@econ.vsu.ru, anna.rodnina@mail.ru
}

\author{
Larisa Nikitina \\ Department of Economics and Organization Management \\ Voronezh State University \\ Voronezh, Russia \\ E-mail: lanikitina@yandex.ru
}

\begin{abstract}
The article examines the formation of the barrier free urban environment for physically challenged people. The authors share the opinion that people with limited mobility should have equal access to the results of implementation of main city functions, such as essential services, entertainment and recreation, government, mercy, knowledge, creativity, interaction between people and nature. For the specified functions, the tasks directly related to people with disabilities are set, and ways of their solution are proposed in a strategy of urban district Voronezh.
\end{abstract}

Keywords-comfortable barrier-free urban environment; biosphere compatibility; strategic development; strategy; goals; methods of implementation

\section{INTRODUCTION}

One of the most important problems of the modern city is the formation of the urban environment, ensuring the compatibility of its components with various aspects of human activity (biosphere compatibility). One of the principles of biosphere compatibility is to meet the diverse needs of the population of the city. In this regard, V. Il'ichev, A. Karimov, V. Kolchunov and other researchers have identified the following seven main functions of the city: essential services, entertainment and recreation, government, mercy, knowledge, creativity, interaction between people and nature [1], [2], [3]. Based on this concept, it is necessary to form an urban environment that is accessible to disabled people (people with limited mobility). Potentially, they should have equal access to the results of the implementation of the above functions.

The composition of facilities to which the access equal in comparison with other social categories has to be ensured, usually does not cover all the specified functions of the city.
Thus, N. Bakaeva, I. Chernyaeva presented quite a wide list of the objects that includes: health care institutions, educational institutions, social welfare institutions, physical training and sports facilities, cultural establishments, communication and information facilities, transport and transport infrastructure facilities, residential structures, consumer market and services facilities, workplaces [4]. The list is very pragmatic. And this is its positive feature. However, entertainment, government, knowledge obviously falls outside the list.

In practice, the focus is on creating a barrier-free environment for people with limited mobility: the physical accessibility of residential buildings, social and infrastructure facilities.

\section{FOREIGN AND DOMESTIC EXPERIENCE IN CREATION OF A BARRIER-FREE ENVIRONMENT}

Apparently it's no coincidence that the earliest documents governing the creation of a barrier-free environment were focused on development of construction standards and regulations. This work has been carried out in Western countries since the 70 s of the twentieth century. In particular, building codes end regulations for the European North have been developed. Their goal is to ensure physical accessibility of buildings and facilities for the elderly and disabled. T. Elokhova notes that the initiator of this work is the Northern Council, which includes representatives of the Nordic countries (Sweden, Denmark, Norway and Iceland) [5]. In Europe and North America documents aimed to improve the accessibility of residential, socio-cultural and infrastructure facilities for disabled people and other people with limited mobility are published and continually refined [5]. 
Practical activities of the Russian town development, residential construction and civil engineering, organization of transport and information services, until recently did not take into account the specific needs of the disabled and was more focused on the formation of an easy of approach living environment in the system of hospital specialized social services $[6,7]$. It can be assumed that Russia's lag behind West in the solution of the specified problem is partly explained by a smaller proportion of the disabled people and other groups with limited mobility. T Elokhova notes that in the Russian Federation the proportion of the disabled people is $9.3 \%$, by comparison it ranges in the countries of Central and Northern Europe from 19.9\% to $32.7 \%$ [5].

\section{Discussion OF THE CURRENT STATE OF THE PROBLEM IN RUSSIA}

Nowadays, the situation improves. In Russia, establishment of a barrier-free environment has become a scope of researchers' attention. E. Khlostova notes that the creation of such an environment is carried out on the basis of the principle of social compensation, which implies benefits and appropriate social services to persons with disabilities [8].

I. Pryadko and K. Orlina note that arrangements for establishment of a barrier-free environment for people with disabilities are being taken in large megacities of Russia. The authors name residential buildings, state and educational facilities, hospitals as the most significant objects. It is important to ensure maximum accessibility of social facilities, including their competent and complex equipment with auxiliary aids and appliances [9].

E. Elokhova draws attention to the need to ensure availability of transport facilities. The area of focus of the city authorities includes the equipment for public transport stops and the vehicles themselves. In particular, the author considers it advisable to replace private shuttle buses with regular buses adapted to transport people with disabilities. The author's viewpoint regarding the need to use the municipal transport for these purposes seems to be not wellgrounded. Private transport can meet the challenge equally effective.

Cited above, T. Elokhova indicates that the Tatarstan program "Barrier-free Environment" focuses on the residential sphere of the city: wheelchair ramps, smooth surface sidewalks, wide doors and other elements of the external environment that make movement of people with limited mobility easier are required [5].

In accordance with the "Guideline and accessibility requirements for the design of the environment, buildings and structures, taking into account the needs of persons with disabilities and other people with limited mobility. Buildings and structures for transportation purposes", a full range of necessary activities is provided at the air-terminal complexes $[10,11]$.

Thus, it can be noticed that extensive theoretical studies, a regulatory framework and a practice of buildings and structures fit-out designed to provide essential services for people with limited mobility are available. The highest level of this function performance is observed at the airports; where, at the transport infrastructure facilities, safety of people with limited mobility in the case of emergency is ensured by means of special safety zones [12].

In practice, there are also quite exotic forms of forming a comfortable environment for persons with disabilities, including the creation of artificial landscapes with color and spatial characteristics, designed to help to achieve the required state of mind [13]. It can be said that such function of a modern city as "interaction between man and nature" is provided. However, it is the exception rather than the rule.

\section{THE STRATEGY OF THE URBAN DisTRICT VORONEZH AND FORMATION OF A COMFORTABLE ENVIRONMENT FOR PERSONS WITH DISABILITIES}

Currently, creation of a comfortable environment for people with disabilities in the Russian regions and municipalities has received significant attention. In this connection, let refer to the Preliminary strategy of the socioeconomic development of the city district, the city of Voronezh for the period until 2035 (hereinafter the Strategy) [14]. The authors of this article participate in the development of this preliminary Strategy and have experience of scientific publications on the problems of strategic planning of administrative-territorial entities [15], [16].

Development of the Strategy assumes a clear structure where the following is specified: a mission, a general goal, strategic goals of the second and third order, objectives, methods of implementation, results (including the most important indicators).

With regard to such city function as establishment of a biosphere compatibility of the urban environment, the most developed unit of the Strategy is "essential services (maintenance of life)". Formation of a comfortable barrierfree environment in priority spheres of life for people with disabilities is specified as one of the strategic goals. However, this goal does not exhaust all variety of work on creation of conditions for inclusion of people with limited mobility in production and other social and economic processes.

In fact, the inclusion of this section of society in public life is planned to be carried out in a wide range of areas, raising not only the level of its essential services, but also participation in production, educational, cultural processes, etc.

One of the tasks in education sector, concerning persons with disabilities, is "improvement of quality of education of students of educational institutions of all levels." In the furtherance of this goal, "laying the groundwork for the inclusive education of children with disabilities" and "laying the groundwork for organizing distance education for children with disabilities" is provided. Due to this combination of problem solving techniques, families with persons with disabilities have the opportunity to choose the method of inclusion in public life - through direct or virtual contact with the active environment. Within this context it 
should be pointed out that virtual contact is becoming increasingly wide-spread among fairly mobile people. This ensures the implementation of the function "knowledge" in the system of biosphere compatibility of the urban environment for people with limited mobility.

In the sphere of culture, the tasks realizing the function "creativity" are the following: "provision of citizens' access to cultural objects and participation in the cultural life of the city district Voronezh" and "development of relevant infrastructure, mitigation of territorial imbalance, and infrastructure development of key cultural institutions".

Such ways to solve the problem as: "expansion of a range of high-quality modern services in the sphere of culture with regard to the needs of the population of the urban district", "modernization of material and technical resources of cultural establishments" and "digitalization" of cultural institutions" have the most pronounced focus on meeting the cultural needs of people with limited mobility.

The function "essential services (maintenance of life)" is planned to be implemented in several the most important ways.

Development of a system of social support and social protection. The strategic goal in this area is formation of a comfortable barrier-free environment in priority spheres of life of people with disabilities.

The most significant task in achievement of this goal is to ensure unhindered access to facilities in priority areas of activity of the disabled and other people with limited mobility.

In the furtherance of this goal, the following methods are of great importance: support to new forms of social services development; custody of adult competent citizens due to the state of health incapable to maintain rights and fulfill their duties at their discretion; development of a network of social institutions for senior citizens, people with disabilities (disabled children), women and children under conditions of hardship; adaptation and equipment of the most demanded objects in education, culture and sports for unhindered use by persons with disabilities. Thus, in this system of tasks and problem solving techniques, not only the function "essential services (maintenance of life)" is realized, but also the function "Mercy" contiguous to it is implemented.

The implementation of these problem solving methods is intended to provide the following results: provision of access to social services in full; expansion of network of integrated institutions for the rehabilitation (habilitation) of persons with disabilities; increase in the accessibility for disabled people and other people with limited mobility of the priority objects to $70 \%$ of the total number of priority objects by 2035; decrease in the level of social orphanhood and family disadvantages.

Digitalization of the sphere of civil protection in emergency situations and maintenance of public security should be recognized as the most important way to implement the function "essential services (maintenance of life)" for people with limited mobility, presented in the
Strategy. Indeed, modern digital technologies to a great degree provide an opportunity to level out differences between persons with varying physical and psychological mobility.

Full-scale implementation of the "essential services (maintenance of life)" function is impossible without inclusion of people with limited mobility in industrial processes. In this regard, such a way of its implementation, presented in the Strategy, as "the growth of supplementary education, including academic disciplines learning to use new technologies, process engineering, work standardizing in various sectors of the economy", is essential. "Practical implementation of information and communication technologies to various life spheres" is intended to do the same.

In development of consumption, encouragement of establishment of trade and service enterprises within walking distance, noted in the Strategy, is essential.

It is of critical importance for maintenance of life of people with disabilities in the framework of balanced spatial development to set in the Strategy such goals as: eliminating inequality between levels of development of urban settlement systems (residential neighborhood, certain territories); improving the quality of the urban environment; formation of spaces with a high level of quality and convenience, and unifying people for exchange of creative ideas. In the case of their successful achievement, a sufficiently complete realization of the functions "maintenance of life", "entertainment and recreation", "interaction between man and nature" is possible.

In our opinion, such problem solving techniques as: transit-oriented development of the city (TOD), implying that new construction facilities are erected within walking distance from public transport stops and transport interchange hubs; renovation of territories, change of functions of space in accordance with the demand of the population and urban needs; development of street infrastructure, green areas and water spaces, social leisure and public business infrastructure, are considered as effective ways.

The main planned results are: polycentric development of the city, creation of local centers with facilities of the social infrastructure, creative industry and modern-quality housing; development of existing and creation of additional recreational areas.

\section{CONCLUSION}

One of the most important areas of implementation of the "maintenance of life" function for people with limited mobility is the improvement of transport infrastructure and transportation. In the line of this goal, the solution of the problem of "forming the structure of municipal transport facilities that meets the requirements of a comfortable urban environment" is planned to be developed.

Development of a project of an intelligent transport system and installation of the elements for collection and 
processing of data on vehicles and road infrastructure is a way to complete the task. The elements include traffic flow detectors; adaptive (smart) traffic lights; parking meters; information boards; automated lighting control systems; GPS / GLONASS systems. In fact, this method is universal and is adequate for the needs of various city population groups, but it is essentially important for people with limited mobility. At the same time, a focused way to solve the problem is also provided. It is renovation of municipal passenger transport facilities and improvement of its structure, in view of economic, environmental characteristics and accessibility for persons with disabilities. A target is to increase a share of municipal passenger transport facilities, equipped to transport people with limited mobility, up to $100 \%$ of total amount of municipal transport facilities by 2035 .

In development of the housing and utilities complex, implementation of a group of actions focused on residential and public landscaping in accordance with regulatory requirements, including providing an accessible environment for people with limited mobility, is of paramount importance.

\section{REFERENCES}

[1] Il'ichev V.A. Principles of Transformation of a City in Biosphere Compatible and Developing the Person // Promyshlennoye I grazhdanskoye stroitel'stvo (Industrial and civil engineering). 2010. No. 6. Pp. 3-13.

[2] Il'ichev V.A.May a city be biospheric compatible and develop humanity? // Arkhitekturaistroitel'stvoMoskvy (Architecture and construction of Moscow).- 2009. V. 544. No. 2. Pp. 8-13.

[3] Suggestions for the Doctrine of Urban Development and Settlement (Strategic Urban Planning) / V.A. Il'ichev, A.M. Karimov, V.I. Kolchunov, V.V. Aleksashina, N.V. Bakaeva, S.A. Kobeleva // Zhilishchnoyestroitel'stvo (Housing construction). 2012. No.1. Pp.211.

[4] Bakaeva N.V., ChernyaevaI.V. Function biospheric compatibility city and their availability to person // Biosfernaya sovmestimost': chelovek, region, tekhnologii (Biosphere compatibility: man, region, technology). 2016. No. 3 (15). Pp. 64-73.

[5] Elokhova T.A. Analysis of foreign experience of target program management in the region (for example, the implementation of "Accessible environment") IzvestiyaKazanskogogosudarstvennogoarkhitekturnostroitel'nogouniversiteta (News of the Kazan State University of Architecture and Civil Engineering). 2015. No. 3(33). Pp. 203-208.

[6] Romanova A.I., Dobroserdova E.A. Modeling and evaluation of foreign experience in improving the quality of construction work and services of business entities // Izvestiya KGASU (News of KSASU). 2015. No. 2 (32). Pp. 338-345.

[7] Romanova A.I., Burkeev D.O. Application of advanced technologies in the quality control of repair work and services // Regional'nayaekonomi-ka: teoriyaipraktika (Regional Economy: Theory and Practice). 2014. No. 34 (361). P. 58-65.

[8] Kholostova E.I. Social policy and social work. M.: Dashkov and Co, 2007. 213 p.

[9] Pryadko I.P., Orlina K.V.City transport in barrier-free architectural planning space for people with limited mobility // Stroitel'stvo: nauka I obrazovaniye (Construction: science and education). 2014. No. 3. P. 5 .

[10] MDS 35-2.200. Guideline and accessibility requirements for the design of the environment, buildings and structures, taking into account the needs of persons with disabilities and other people with limited mobility. Buildings and structures for transportation purposes. M., 2000. 42 p.
[11] Nigmatullina R.V., Sosnovskikh L.V. Designing of an air terminal complexes that has a requirement to accommodate people with disabilities // Sovremennyye tekhnologii v stroitel'stve. Teoriyaipraktika (Modern technologies in construction. Theory and practice). 2017. V. 1. Pp. 55-62.

[12] Collection of regulatory legal acts and reference documents: a methodical manual for training employees of ITU institutions and other organizations on the issues of accessibility to persons with disabilities and the facilities on which they are provided, while providing the necessary assistance. M., 2015. $291 \mathrm{p}$.

[13] Ivanova N.V. Guidelines on greening urban space for disabled people in training landscape professional // Novyyeideinovogoveka: materialymezhdunarodnoynauchnoykonferentsiiFAD TOGU (New Ideas of the New Century: Papers of the International Scientific Conference FAD PNU). 2016. V. 2. Pp. 444-449.

[14] The strategy of socio-economic development of the city district of Voronezh for the period up to 2035 (draft). Available at: voronezhcity.ru >communications/main_topics.

[15] Getmantsev T.V., Lanskaya D.V., Myasnikova T.V., Treshevsky Y.I. The Current Practice of the Strategic Planning in Russian Regions: Innovative Model of Strategic Planning "Galaxy 7 × 7 × 7" of the Leontief Centre-AV Group Consortium and Experience of Its Approbation in Krasnodar Krai// The Future of the Global Financial System: Downfall or Harmony Lecture Notes in Networks and Systems. Volume 57 / Elena G. Popkova Editor // Springer Nature Switzerland AG. Cham, Switzerland. - 2018. Pp. 105-113.

[16] Bitarova M.A., GetmantsevK.V., IlyasovaE.V., KrylovaE.M., Treshchevsky Y.I. Factors of Socio-Economic Development of Rural Regions in the Area of Influence of City Agglomerations // The Future of the Global Financial System: Downfall or Harmony Lecture Notes in Networks and Systems. Volume 57 / Elena G. Popkova Editor // Springer Nature Switzerland AG. Cham, Switzerland. 2018. Pp. 183-194. 